\title{
Modeling Oil Palm Nutrient Management Using Linear Goal Programming
}

\author{
Rida Agustina*, Habibis Saleh, M. D. H. Gamal \\ Department of Mathematics, University of Riau, Pekanbaru, Indonesia
}

Email address:

ridaagustina@ymail.com (R. Agustina),dr.habibissaleh@gmail.com (H. Saleh), mdhgamal@unri.ac.id (M. D. H. Gamal)

To cite this article:

Rida Agustina, Habibis Saleh, M. D. H. Gamal. Modeling Oil Palm Nutrient Management Using Linear Goal Programming. Applied and Computational Mathematics. Vol. 4, No. 5, 2015, pp. 374-378. doi: 10.11648/j.acm.20150405.17

\begin{abstract}
This paper describes a mathematical model for a good mixture of fertilizer levels using goal programming technique for oil palm plantations so that the oil palm plants produce high quality fruit. Goal programming used is preemptive goal programming. Computational results indicates that the determination of the optimal the mix of fertilizer using goal programming techniques is very effective because this technique is able to meet any goals expected in the oil palm plantations.
\end{abstract}

Keywords: Mixing Model, Preemptive Goal Programming, Mixture of Fertilizers

\section{Introduction}

Oil palm (elaeis guineensis) require nutrients both micro and macro that can be obtained from the soil. Nutrients deficiency can decrease crop productivity even can lead the palm trees to the death. This condition may be prevented or improved by adding nutrients to the soil by applying the fertilizers. All fertilizers are labeled with the use levels of total nitrogen, phosphate and potassium. The good combination of fertilizers is needed for the oil palm plantations to produce high quality oil palm trees so as to increase the crop production and economics of farmers.

This study involves more than one objective functions; that is, minimizing the amount of fertilizer financing expenses, maximizing production, minimizing the upper limit of the nutrient contents in the fertilizer of oil palm plants and maximizing the lower limit of the nutrient contents. Goal programming can be used since it can solve problems with multi objectives stated as goals. Goal programming has been widely applied in various disciplines including economics, administration, agriculture, health and other fields.

Jagadesswaran et al. (2005) study the influence of NPK fertilizers in nutrient efficiently in Turmerik. The result shows that the use of nutrients is efficient, $i . e$. agronomical efficiency, recovery is achieved and achieved productivity factor increases by applying a source of NPK in the form of fertilizer tablets. Nyathi and Campbell (1995) study the result of the interaction of leaf litter, manure and inorganic fertilizers in Zimbabwe. The study was conducted during two seasons to evaluate the effects of leaf litter, manure, compound D of ha-fertilizer and combinations on the growth of corn and the harvesting on the sandy soil at Makoholi Trial Station, Zimbabwe.

Wheller and Russel (1997) develop the goal programming methods for agricultural planning in the UK. Jafari and Qhorbanali (2008) use a goal programming technique to optimize paddy (rice) farmland in Iran. When using the goal programming an optimal solution is obtained. In addition, for farmers, they do not only want to increase the maximum results but minimizing the cost of fertilizer for plants and would like to develop the size of the crop area further. Ghosh and Dinesh (2005) formulate the model of goal programming in nutrient management for rice production in West Bengal. Hassan et al. (2013) optimize fertilizer compounds and minimize the cost production of cucumbers using goal programming approach.

In this paper we present the use of goal programming techniques for managing nutrients in the oil palm plantations in Riau Province, Indonesia.

\section{Mathematical Model}

Oil palm is an important industrial plant producing cooking oil, industrial oil, and fuel (biodiesel). Oil palm plantations generate large profits so that many forests and old plantations changed into oil palm plantations. Indonesia is the largest palm oil producer in the world (Corley and Tinker, 2003). In Indonesia oil palm plantations spread in the regions of Aceh, East Coast of Sumatra, Java and Sulawesi. 
Riau Province is a number one palm oil producer province in Indonesia with a land area of approximately 2.4 million hectares spreading in Riau Province. There are several reasons why the Regional Government of Riau puts palm oil as the mainstay, among others: first, in terms of physical and environmental circumstances, Riau area allows for the development of oil palm plantations. Geographically Riau area is relatively flat that facilitates the management and can reduce the cost of production; second, soil condition allows for planting oil palm that yields higher production than other regions; third, in terms of marketing products, Riau has the advantages of its strategic location in the international markets, namely Singapore; fourth, Riau has a development area of Western Indonesia with the opening of the cooperation between Indonesia-Malaysia- Singapore Growth
Triangle (IMS-GT) and Indonesia-Malaysia-Thailand Growth Triangle (IMT-GT), it means that there are more open favorable market opportunities; and fifth, based on the results achieved show that oil palm gives higher income to farmers compared with other agricultural crops.

\section{Model Formulation}

Maximum and minimum requirements of nutrients in Table 1 recommended by the Plantation Office of Riau Province are as follows: $150-180 \mathrm{~kg} / \mathrm{ha}$ for nitrogen $(\mathrm{N})$, $110-140 \mathrm{~kg} / \mathrm{ha}$ of phosphorus (P), and $90-130 \mathrm{~kg} / \mathrm{ha}$ of potassium $(\mathrm{K})$. There are eight decision variables in the contents of fertilizer that should be considered in accordance with the Indonesian National Standard where mass fertilizer in $\mathrm{kg}$ per hectare is presented in Table 1.

Table 1. Type of fertilizer, the price, and the content of NPK.

\begin{tabular}{|c|c|c|c|c|c|c|c|c|}
\hline Index & 1 & 2 & 3 & 4 & 5 & 6 & 7 & 8 \\
\hline Type of Fertilizer ( j ) & UREA & SSP & MOP-KCL & SOP- ZK & DAP & NPK (12-12-17-2) & NPK (15-15-6-4) & NPK (15-15-15) \\
\hline Price (IDR/kg) & 6,000 & 7,000 & 7,000 & 7,000 & 7,000 & 10,000 & 10,000 & 10,000 \\
\hline \multicolumn{9}{|l|}{ Contents $(\%)$} \\
\hline $\mathrm{P}$ & & 18 & & & 46 & 12 & 15 & 15 \\
\hline K & & & 60 & 50 & & 17 & 6 & 15 \\
\hline
\end{tabular}

a) Decision variables

$x_{j}:=$ The amount of fertilizer $j$ in kg for one hectare of oil palm plantation, $(j=1,2, \ldots, 8)$.

b) Coefficients and constants

$c_{j}:=$ The cost of fertilizer per unit ${ }^{x_{j}}(j=1,2, \ldots, 8)$ $(\mathrm{IDR} / \mathrm{kg})$

$A_{j}^{(q)}:=$ The percentage of nutrient $q(q=1,2,3)$ in fertilizer $j(\%)$

$U^{(q)}:=$ The upper limit of nutrients $q(q=1,2,3)$ in fertilizer $(\mathrm{kg} / \mathrm{ha})$

$L^{(q)}:=$ Lower limit of nutrient $q \quad(q=1,2,3)$ in fertilizer $(\mathrm{kg} / \mathrm{ha})$

$T:=$ Total expenses of fertilizer in 1 year in Indonesian currency (IDR)

$Y:=$ The production of oil palm from the year 2004-2013 (tons)

$a, b:=$ Factors affecting the value of production of oil palm

c) Goals constraints

In any goal programming constraint there are variables and the deviation of $d_{p}^{+}$and $d_{p}^{-}$with $d_{p}^{+}$is above the target and $d_{p}^{-}$is below the target.

i. Minimize the amount of fertilizers whose costs are less than or equal to the amount of budgeted expenditures.

ii. The total cost should be less than or equal to the available budget. The constraints are written as

$$
\sum_{j=1}^{8} c_{j} x_{j} \leq T
$$

In the goal equation it can be written as

$$
\sum_{j=1}^{8} c_{j} x_{j}+d_{1}^{-}-d_{1}^{+}=T .
$$

The devision variable $d_{1}^{+}$is to be minimized so that the expected goal is achieved by reducing the expenditures and minimizing the excessive targets.

iii. Production results in this case assume that the relationship between the use of fertilizers and production is linearly correlated. Therefore, the production of palm fruit depends on the quantity of fertilizer needed. Linear equations used are based only on data from the year 2004 to 2013. Under normal circumstances, the effect of nutrients in the soil is corresponding to the production of palm fruit formulated in the form $Y=a x+b$. This relationship can be obtained by solving linear equations written as follows:

$$
a \sum_{j=1}^{8} x_{j}=Y-b
$$

In the goal equation it can be written as

$$
a \sum_{j=1}^{8} x_{j}+d_{8}^{-}-d_{8}^{+}=Y-b .
$$


To obtain maximum production results, an negative deviational variable is minimized, namely $d_{8}^{-}$.

iv. The upper limit of nutrients is for ensuring normal growth in fertilizer combinations, there should be an upper limit for each nutrient in combination, that is

$$
\sum_{j=1}^{8} A_{j}^{(q)} x_{j} \leq U^{(q)}
$$

Then minimize the use of excess nutrients in fertilizer. In goal programming form, the equations are written as

$$
\sum_{j=1}^{8} A_{j}^{(q)} x_{j}+d_{p}^{-}-d_{p}^{+}=U^{(q)}
$$

Minimize the devisional variables $d_{p}^{+}$with $q=1,2,3$ and $p=2,3,4$.

v. Lower limit of nutrients is to be maximized as to avoid damage to the oil palm fruits and to ensure good results from oil palm crops. It must be presented in fertilizer combination as the constraint

$$
\sum_{j n=1}^{8} A_{j}^{(q)} x_{j} \geq L^{(q)}
$$

The content of nutrients in fertilizers may not exceed the lower limit of nutrients. In the form of goal programming, these equations can be written as follows:

$$
\sum_{j=1}^{8} A_{j}^{(q)} x_{j}+d_{p}^{-}-d_{p}^{+}=L^{(q)}
$$

Minimize the devisional variables $d_{p}^{-}$with $q=1,2,3$ and $p=5,6,7$.

\section{Computational Results}

Minimum cost of fertilizers obtained in this equation is formed from the content of the fertilizer at per kilogram price for each fertilizer. The value of the right hand side of the equation (1) is the cost of the total budget of the fertilizers on oil palm plantation in Riau in the year 2013 obtained from the number of each $\mathrm{kg}$ of the fertilizer used per hectare of oil palm plantation at the age of $0-9$ years.

Estimated cost $\mathrm{T}$ of the fertilizers is IDR17.752.500, so the budgetary constraints can be written as follows:

$$
\begin{aligned}
& 6.000 x_{1}+7.000 x_{2}+7.000 x_{3}+7.000 x_{4}+7.000 x_{5} \\
& +10.000 x_{6}+10.000 x_{7}+10.000 x_{8} \leq 17.752 .500
\end{aligned}
$$

By adding a pair of deviational variables, the constraint (1) becomes

$$
\begin{aligned}
& 6.000 x_{1}+7.000 x_{2}+7.000 x_{3}+7.000 x_{4}+7.000 x_{5} \\
& +10.000 x_{6}+10.000 x_{7}+10.000 x_{8}+d_{1}^{-}-d_{1}^{+}=17.752 .500
\end{aligned}
$$

To increase the yield of palm fruit production under normal conditions, the use of fertilizer is needed to optimize nutrients into the soil. The $Y$ value was obtained from the average yield of palm fruit production of 6,058,827.2 tonnes divided by oil palm land area in Riau province in 2013 amounted to 2.4 million hectare based on the data from the Office of Plantation of Riau Province, so that $Y$ value is obtained at 2,524,511.333. The $Y$ value is rejected by getting the value of $a$ and $b$; that is, factors that affect the production obtained from the regression equation with $a=0.91$ and $b=$ $3,275,189$. Goals equality for production is written as follows:

$$
0,91 \sum_{j=1}^{8} x_{j}+d_{8}^{-}-d_{8}^{+}=Y-3.275 .189
$$

The maximum and minimum of nutrients N-P-K requirements recommended by the Office of Plantation are presented in the constraints below. Each of the lower limit of $\mathrm{N}, \mathrm{P}$, and $\mathrm{K}$ is presented respectively in the constraints

$$
\left.\begin{array}{l}
0,46 x_{1}+0,18 x_{5}+0,12 x_{6}+0,15 x_{7}+0,15 x_{8} \geq 150 \\
0,18 x_{2}+0,46 x_{5}+0,12 x_{6}+0,15 x_{7}+0,15 x_{8} \geq 110 \\
0,6 x_{3}+0,5 x_{4}+0,17 x_{6}+0,6 x_{7}+0,15 x_{8} \geq 90
\end{array}\right\}
$$

By adding a pair of deviation variables, the constraints (2) become

$$
\begin{gathered}
0.46 x_{1}+0,18 x_{5}+0,12 x_{6}+0.15 x_{7}+0,15 x_{8}+d_{2}^{-} d_{2}^{+}=150 \\
0,18 x_{2}+0,46 x_{5}+0,12 x_{6}+0.15 x_{7}+0,15 x_{8}+d_{3}^{-} d_{3}^{+}=110 \\
0,6 x_{3}+0,5 x_{4}+0,17 x_{6}+0.6 x_{7}+0,15 x_{8}+d_{4}^{-} d_{4}^{+}=90
\end{gathered}
$$

For each of the upper limit of N- P - K are presented in the following constraints:

$$
\left.\begin{array}{l}
0,46 x_{1}+0,18 x_{5}+0,12 x_{6}+0,15 x_{7}+0,15 x_{8} \leq 180 \\
0,18 x_{2}+0,46 x_{5}+0,12 x_{6}+0,15 x_{7}+0,15 x_{8} \leq 140 \\
0,6 x_{3}+0,5 x_{4}+0,17 x_{6}+0,6 x_{7}+0,15 x_{8} \leq 130
\end{array}\right\}
$$

By adding a pair of deviational variables, the constraints (3) become

$$
\begin{aligned}
& 0.46 x_{1}+0,18 x_{5}+0,12 x_{6}+0.15 x_{7}+0,15 x_{8}+d_{5}^{-} d_{5}^{+}=180 \\
& 0,18 x_{2}+0,46 x_{5}+0,12 x_{6}+0.15 x_{7}+0,15 x_{8}+d_{6}^{-} d_{6}^{+}=140 \\
& 0,6 x_{3}+0,5 x_{4}+0,17 x_{6}+0.6 x_{7}+0,15 x_{8}+d_{7}^{-} d_{7}^{+}=130
\end{aligned}
$$

\section{Priority Structure}

The function of goals is in the minimum form and only includes deviational variables. The highest priority goal is to minimize the total cost in excess of fertilizer combination and 
increase the plantation production, the second priority goal is to maximize the utilization of the lower limit of the nutrients, while the third priority goal is to minimize the more use of the upper limit of the nutrients.

Corresponding to the decision making variables, structure priority problems can be defined as follows:

$$
P_{1}: \text { Minimize }\left(d_{1}^{+}, d_{8}^{-}\right)
$$

Parameter $d_{1}^{+}$is the target above the goal to be minimized; that is, the excessive costs so that the expected goals are achieved. Parameter $d_{8}^{-}$is also to be minimized so that the oil palm fruits production increases.

$$
P_{2}: \operatorname{Minimize}\left(d_{2}^{-}, d_{3}^{-}, d_{4}^{-}\right)
$$

Parameter $d_{p}^{-}$is the target below goals to be minimized; i.e. nutrient is not less than a predetermined so the expected goals are achieved.

$$
P_{3}: \text { Minimize }\left(d_{5}^{+}, d_{6}^{+}, d_{7}^{+}\right)
$$

Parameter $d_{p}^{+}$is the target above the goal to be minimized so as not to exceed the limit of nutrients so that the expected goals are achieved.

This model of goal programming has been applied with LINGO software. Priorities of achievement in accordance with the optimal decision is shown in Table 2.

Table 2. riorities of Achievement.

\begin{tabular}{lll}
\hline Priority & Description & Achievement \\
\hline$P_{1}$ & $\begin{array}{l}\text { Minimize the total cost of fertilizer } \\
\text { combinations and increase the palm } \\
\text { fruit production }\end{array}$ & Achieved \\
$P_{2}$ & $\begin{array}{l}\text { Maximize the use of nutrient lower } \\
\text { limits. }\end{array}$ & Achieved \\
$P_{3}$ & $\begin{array}{l}\text { Minimize the excess of nutrient upper } \\
\text { limits. }\end{array}$ & Achieved \\
\hline
\end{tabular}

Optimal solution obtained is $x_{1}=86.96 \mathrm{~kg} / \mathrm{ha}$, $x_{7}=44.44 \quad \mathrm{~kg} / \mathrm{ha}, \quad x_{8}=688.89 \quad \mathrm{~kg} / \mathrm{ha}$, $d_{1}^{+}=d_{2}^{-}=d_{3}^{-}=d_{4}^{-}=0, \quad d_{5}^{+}=d_{6}^{+}=d_{7}^{+}=0 \quad$ and $d_{8}^{-}=0$. There are three kinds of fertilizer; i.e. urea, NPK (15-15-6) and NPK (15-15-15) which should used in oil palm plantations and it can be seen that the N-P-K applied to each of $150 \mathrm{~kg} / \mathrm{ha}$ of nitrogen, $110 \mathrm{~kg} / \mathrm{ha}$ phosphate and $90 \mathrm{~kg} / \mathrm{ha}$ potassium. The first priority goal that minimize the excess of the target to be expected from the total cost on fertilizer combination is achieved when $d_{1}^{+}$is zero, and the total costs is reduced by $d_{1}^{-}$as much as IDR9,897,428 from IDR17,752,500 to IDR7,855,072 and production output increases by 751.424 tonnes of palm fruit. The second priority goal is to maximize the use of the lower limit of the nutrients which is also achieved when $d_{2}^{-}, d_{3}^{-}, d_{4}^{-}$all are zero. Last, when all the positive deviational variables is zero then the third priority to minimize the use of excess nutrients from the upper limit is also achieved.

\section{Conclusions}

This study attempts to overcome nutrient management issues of oil palm plants using a model of linear goal programming. The cost of fertilizer produced is significantly reduced. The aim of optimizing fertilizers N-P-K and minimizing the cost of production using goal programming approach has been achieved. A goal programming approach has been proved to be a good technique and useful for agricultural engineers to guide farmers in reducing the cost of production thereby increasing their profits. Further research on the production based on nutrient management may be implemented to other plants.

\section{Acknowledgements}

The authors thank Dr. Nelvia from Faculty of Agriculture, University of Riau who gave many inputs on nutrient contents and combination of fertilizers to the oil palm plants. The authors also thank the Office of Plantation of Riau Province for providing us the data and information needed in preparing and writing this paper.

\section{References}

[1] Adi, S. P, Kaya dengan Bertani Kelapa Sawit, Pustaka Baru, Jakarta, 2011

[2] Corley, R. H. V. and Tinker, P. B. 2003. The Oil Palm, Wiley-Blackwell, USA.

[3] Ghosh, D. and Dinesh, K. 2005. Goal Programming Formulation in Nutrient Management for Rice Production in West Bengal, International Journal of Production Economics, 95: 1-7.

[4] N. Hassan, N., Hassan, K. B., Yatim, S. S., and Yusof, S. A. 2013. Optimizing Fertilizer Compounds and Minimizing the Cost of Cucumber Production Using the Goal Programming Approach, American-Eurasian Journal of Sustainable Agriculture, 7: 45-49.

[5] Jagadeeswaran, R., Murugappan, V., and Govindaswamy, M. 2005. Effect of Slow Rehease NPK Fertilizer Sources on the Nutrient Use Efficiency in Turmeric, World J. Agric. Sci, 1(2005), 65-69.

[6] Jafari, H., and Qhorbanali, R. 2008. An Optimal Model Using Goal Programming for Rice Farm, Applied Mathematical Sciences, 23: 1131-1136.

[7] Nyathi, P., and Campbell, B. M. 1995. Interaction Effect of Tree Leaf Litter, Manure and Inorganic Fertilizer on the Performance of Maize in Zimbabwe, African Crop Science Journal, 3: 451-456.

[8] Orumnie, U. C. and D. W. U. Ebong, Another Efficient Method of Solving Weighted Goal Programming, Asian Journal of Mathematics and Applications. 2013,1-11.

[9] Siswanto, Operation Research Jilid satu. Erlangga, Jakarta, 2007. 
[10] Taha, H.A, Operations Research and Introduction. Edisi ke-7. New Jersey, Prentic Hall, 2003.
[11] Wheeler, B. M., and Russell, J. R. M. 1997. Goal Programming and Agricultural Planning, Operational Research Quarterly, 28: 21-32. 